\title{
Aplicação de recobrimento prolonga a qualidade pós-colheita de laranja 'Valência Delta' durante armazenamento ambiente ${ }^{1}$
}

\author{
Application of coating extends postharvest quality in the 'Valencia Delta' orange \\ during ambient storage
}

\author{
Gerlândia da Silva Pereira ${ }^{2 *}$, Francisca Ligia de Castro Machado ${ }^{3}$ e José Maria Correia da Costa ${ }^{4}$
}

\begin{abstract}
RESUMO - O objetivo desse trabalho foi avaliar o efeito da aplicação de cera à base de carnaúba na qualidade e conservação da laranja cv. 'Valência Delta', produzida em área de clima semiárido durante o armazenamento ambiente $\left(24{ }^{\circ} \mathrm{C} \pm 2\right.$ e $40 \% \pm 5$ U.R.). A influência da utilização do recobrimento nas propriedades físicas (perda de massa, umidade da casca e coloração do flavedo) e físico-químicas (sólidos solúveis, acidez titulável, pH, relação sólidos solúveis/acidez titulável, ácido ascórbico, flavonóides amarelos e polifenóis totais) foi avaliada a cada quatro dias, por um período de 28 dias. Observou-se perda de massa crescente durante o armazenamento; no entanto, os frutos recobertos perderam massa a taxas bem menores que os frutos controle. Em concordância, a umidade da casca diminuiu durante o armazenamento, sendo mais pronunciada nos frutos controle. Os teores de sólidos solúveis, acidez titulável, ácido ascórbico, flavonóides amarelos e polifenóis totais aumentaram, enquanto a relação sólidos solúveis/acidez titulável e pH decresceram ao longo do armazenamento. A aplicação de recobrimento à base de carnaúba prolongou a vida útil pós-colheita da laranja 'Valência Delta', cultivada no Estado do Ceará, através de uma significativa redução na perda de massa, intensificação do brilho do flavedo e manutenção das propriedades físicas e físico-químicas durante o armazenamento ambiente.
\end{abstract}

Palavras-chave: Laranja. Cera de carnaúba. Pós-colheita.

\begin{abstract}
The objective of this study was to evaluate the effect of the application of carnauba-based wax on the quality and conservation of the Orange cv. Valencia Delta produced in an area of semi-arid climate, during ambient storage $\left(24 \pm 2{ }^{\circ} \mathrm{C}\right.$ and $40 \% \pm 5 \mathrm{RH}$ ). The influence of the use of the coating on the physical properties (weight loss, peel moisture and flavedo colouration) and the physicochemical properties (soluble solids, titratable acidity, $\mathrm{pH}$, soluble solids / titratable acidity ratio, ascorbic acid, yellow flavonoids and total polyphenols) was evaluated every four days for a period of 28 days. An increasing weight loss was seen during storage, the coated fruits however, lost weight at far lower rates than the control fruits. Accordingly, peel moisture decreased during storage, being more pronounced in the control fruits. The levels of soluble solids, titratable acidity, ascorbic acid, yellow flavonoids and total polyphenols increased, while the ratio of soluble solids to titratable acidity and the $\mathrm{pH}$ decreased during storage. The application of a carnauba-based coating prolonged the postharvest life of the "Valencia Delta' orange grown in the state of Ceará, through a significant reduction in weight loss, enhancement in the brightness of the flavedo and maintenance of the physical and physicochemical properties during ambient storage.
\end{abstract}

Key words: Orange. Carnauba wax. Postharvest.

\footnotetext{
*Autor para correspondência

'Recebido para publicação em 01/06/2012; aprovado em 25/02/2014

Parte da Dissertação de Mestrado do primeiro autor apresentada à Universidade Federal do Ceará

${ }^{2}$ Departamento de Ciência e Tecnologia de Alimentos, Centro de Ciências Agrárias, Universidade Federal do Ceará, Fortaleza-CE, Brasil, gerlandiasp@ibest.com.br

${ }^{3}$ Departamento de Fitotecnia. Instituto Federal de Educação, Ciência e Tecnologia, Campus Tianguá, Tianguá-CE, Brasil, ligiacmachado@yahoo.com ${ }^{4}$ Departamento de Biotecnologia e Indústrias Alimentares, Centro de Ciências Agrárias, Universidade Federal do Ceará, Fortaleza-CE, Brasil, correiacostaufc@gmail.com
} 


\section{INTRODUÇÃO}

No Brasil, a região Nordeste ocupa o segundo lugar em produção de citros, sendo os estados da Bahia e Sergipe seus principais. O cultivo de citros no Nordeste tem grande destaque na fruticultura do país e na economia da região. O semiárido nordestino se destaca através da agricultura irrigada, sendo a região do Baixo Jaguaribe uma área potencialmente aproveitável por apresentar bom suprimento de recursos hídricos e solos profundos, que podem ser explorados com tecnologias de irrigação (FRANÇA, 2010). Nessa região, as culturas de banana, melão e manga têm grande destaque, além do cultivo de variedades cítricas, incluindo laranjas cv. 'Valência Delta', que vêm sendo implantadas nesse polo agroindustrial.

A laranjeira 'Valência Delta' destaca-se pela qualidade e suculência (AULER; FIORI-TUTIDA; SCHOLZ, 2009) e os frutos apresentam excelente qualidade nos países que os produzem, como África do Sul, Argentina, Estados Unidos, Uruguai; tanto para produção de suco como para o consumo in natura (OLIVEIRA; NAKASU; SCIVITTARO, 2008). Vale ressaltar que essa variedade não é comum à região do semiárido nordestino brasileiro. Dessa forma, este estudo é pioneiro no que diz respeito à caracterização dos frutos, assim como à conservação pós-colheita dos mesmos através do uso de tecnologias já utilizadas com sucesso em outras variedades de citros cultivados sob outras condições climáticas.

A aparência, o sabor e o valor nutritivo estão entre os atributos de qualidade mais exigidos pelo consumidor. Os teores de ácidos orgânicos, sólidos solúveis e pH, são alguns dos parâmetros de qualidade em frutos. Esses parâmetros são influenciados por fatores como época, local de colheita, variedade, tratos culturais e manuseio pós-colheita (RODOLFO JÚNIOR et al., 2007). As mudanças físicas e físico-químicas são as principais causas da perda de qualidade durante o armazenamento. Por isso, tornam-se necessários o armazenamento adequado e a utilização de tecnologia pós-colheita que permitam preservar a qualidade dos frutos. Para manter a qualidade e estender a vida útil de produtos frescos, tem sido explorado o uso de recobrimentos na superfície externa dos mesmos, incluindo os cítricos. O recobrimento aplicado no fruto apresenta diferentes taxas de permeabilidade ao $\mathrm{O}_{2}, \mathrm{CO}_{2}$ e vapor d'água em função das propriedades da matéria-prima, concentração e espessura da película (HAGENMAIER, 2005). A utilização de cera objetiva adicionar brilho e reduzir a perda de água, principalmente da casca dos frutos (JOMORI et al., 2003).

Este estudo objetiva avaliar o efeito da aplicação de cera à base de carnaúba na qualidade e conservação da laranja cv. 'Valência Delta', produzida em área de clima semiárido, Estado do Ceará, durante o armazenamento ambiente.

\section{MATERIAL E MÉTODOS}

\section{Origem, classificação e preparo das amostras}

Frutos da laranjeira 'Valência Delta' [Citrus sinensis (L.) Osbeck] enxertada em porta-enxerto citrumelo 'Swingle' [Citrus paradisi Macfad. x Poncirus trifoliata (L.) Raf.] foram colhidos em Limoeiro do Norte $\left(5^{\circ} 20^{\prime}\right.$ de latitude Sul e $38^{\circ} 5^{\prime}$ e de longitude Oeste), Estado do Ceará, em novembro de 2010. Essa área caracteriza-se como tendo temperatura média anual de $28,5{ }^{\circ} \mathrm{C}$; chuvas anuais com ocorrências irregulares de $772 \mathrm{~mm}$, umidade relativa de $62 \%$ e radiação solar de 3.030 horas (DNOCS, 2011). Os frutos foram colhidos pela manhã, acondicionados em caixas de papelão e transportados para a Universidade Federal do Ceará, departamento de Tecnologia de Alimentos. Os frutos foram selecionados quanto ao estádio de maturação, eliminando-se qualquer desuniformidade quanto à forma, tamanho, coloração e injúrias e apresentaram na colheita, peso médio de $314 \mathrm{~g}$, diâmetro de 81,90 mm e ângulo hue de 113,89. Após a seleção, os frutos foram lavados com água corrente.

\section{Aplicação dos tratamentos e armazenamento das amostras}

Após seleção e higienização os frutos foram divididos em dois lotes iguais. O primeiro lote foi recoberto com cera à base de carnaúba (Aruá Tropical ${ }^{\circledR}$ ), diluído em água destilada (1v: 1v), enquanto o segundo serviu como controle. Os frutos foram armazenados sob temperatura ambiente $\left(24{ }^{\circ} \mathrm{C} \pm 2\right.$ e $40 \% \pm 5$ U.R $)$. As análises foram realizadas após a aplicação dos tratamentos e a cada quatro dias, por um período 28 dias.

\section{Características estudadas}

Estudaram-se as características físicas e fisicoquímicas dos frutos. As análises físicas foram perda de massa, coloração externa e teor de umidade da casca, enquanto as físico-químicas foram teores de sólidos solúveis (SS) e acidez titulável (AT), relação SS/AT, $\mathrm{pH}$, teores de ácido ascórbico, flavonóides amarelos e polifenóis totais.

A perda de massa foi determinada por pesagem em frutos previamente numerados e calculada a partir das diferenças de massa das unidades experimentais observadas entre o momento da instalação do experimento $\mathrm{e}$ as avaliações realizadas durante $\mathrm{o}$ armazenamento, sendo os resultados expressos em porcentagem (\%). A coloração do flavedo foi realizada na região equatorial dos frutos, previamente marcadas, utilizando-se duas medições por fruto; o colorímetro Minolta CR-300 foi utilizado e foram obtidos os valores de $\mathrm{L}, \mathrm{a}^{*} \mathrm{e} \mathrm{b}^{*}$. Os valores de chroma e ângulo hue foram calculados segundo McGuire (1992). 
O teor de umidade da casca foi calculado com base no peso seco. Cerca de $5 \mathrm{~g}$ de amostra foram pesados em recipiente de alumínio e seca em estufa de ar quente a $80^{\circ} \mathrm{C}$ até a obtenção da massa constante. Os teores de sólidos solúveis foram determinados em refratômetro digital (Modelo PR-100 Pallete, Atago Co.) segundo Association of Official Analytical Chemists (1995) e os resultados foram expressos em ${ }^{\circ}$ Brix. $\mathrm{O} \mathrm{pH}$ foi determinado em potenciômetro digital (ASSOCIATION OF OFFICIAL ANALYTICAL CHEMISTS, 1995) e os teores de acidez titulável foram determinados por titulometria com solução de $\mathrm{NaOH}$ 0,1M (INSTITUTO ADOLFO LUTZ, 2004) com os resultados expressos em porcentagem de ácido cítrico. A relação SS/AT foi obtida através do quociente entre as variáveis SS e AT. As medições de ácido ascórbico foram realizadas segundo a metodologia descrita por Strohecker e Henning (1967) e os resultados expressos em (mg ácido ascórbico.100 $\mathrm{g}^{-1}$ de suco). Os flavonóides amarelos foram determinados pelo método de Francis (1982) e as leituras foram feitas em espectrofotômetro a $374 \mathrm{~nm}$ com os resultados expressos em mg. $100 \mathrm{~g}^{-1}$. Os teores de polifenóis totais foram determinados segundo a metodologia descrita por Bucic-Kojic et al. (2007) e as leituras foram feitas em espectrofotômetro a $765 \mathrm{~nm}$ com os resultados expressos em mg GAE. $100 \mathrm{~mL}^{-1}$.

\section{Delineamento experimental e testes estatísticos}

O delineamento experimental foi o inteiramente casualizado em parcelas subdivididas, utilizando-se dez repetições para análises não-destrutivas, perda de massa e coloração do flavedo, e quatro repetições para as demais análises estudadas.

A parcela principal foi composta pelos tratamentos, enquanto as sub-parcelas foram compostas pelas durações de armazenamento. Foi realizada a análise de variância e o teste de Tukey $(\mathrm{p} \leq 0,05)$. Regressões lineares foram usadas para descrever as tendências durante o armazenamento $\left(\mathrm{R}^{2} \geq 70 \%\right)$, utilizando-se o software SISVAR, versão 4.1.

\section{RESULTADOS E DISCUSSÃO}

A perda de massa dos frutos durante o armazenamento foi influenciada pela interação dos fatores aplicação de recobrimento e durações de armazenamento $(\mathrm{p}<0,05)$. De fato, apesar de ter sido observado perda de massa crescente nos dois tratamentos, os frutos recobertos com cera perderam menos massa que os frutos controle por todo o período de armazenamento (Figura 1).

Ao término do período de 28 dias de armazenamento os frutos controle perderam aproximadamente $26 \%$ da massa inicial, enquanto nos frutos recobertos esta perda foi reduzida para apenas $14 \%$. A perda de massa encontra-se
Figura 1 - Evolução da perda de massa em laranja 'Valência Delta' armazenada sob condição ambiente com e sem recobrimento

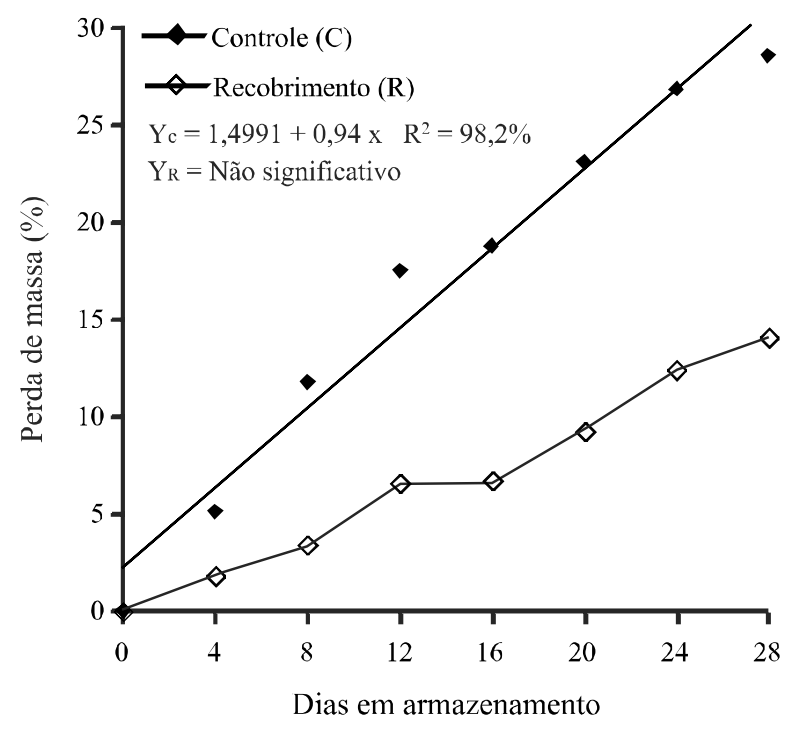

diretamente relacionada à perda de umidade, reconhecida como principal causa de deterioração nos cítricos e resultando em perdas quantitativas e qualitativas. De modo geral, perda de umidade superior a $6 \%$ pode tornar o fruto inadequado para a comercialização por causar perceptível perda na qualidade visual dos cítricos, geralmente ocasionada por enrugamento e desidratação da casca (LADANIYA, 2008). Tomando-se como base a porcentagem de perda de umidade citada acima, a utilização de cera à base de carnaúba em laranja 'Valência Delta' proporcionou uma menor perda de massa, prologando a vida útil desses frutos por até 12 dias a mais que os frutos controle, pois o recobrimento modificou a condição atmosférica da fruta e evitou a perda de umidade. Estes resultados concordam com os reportados por Malgarim, Cantillano e Treptow (2007), em que a aplicação de cera em laranja doce cv. Navelina reduziu a perda de massa durante o armazenamento.

A luminosidade do flavedo dos frutos foi influenciada pela interação entre os fatores aplicação de recobrimento e durações de armazenamento $(\mathrm{p}<0,05)$. Os valores de luminosidade cresceram durante o armazenamento para ambos os tratamentos, apresentando valores superiores a 50 no decorrer do mesmo, indicando que a casca dos frutos tornouse mais clara. Os frutos controle tornaram-se muito mais claros ao longo do armazenamento, devido provavelmente, ao metabolismo acelerado ocasionado pelas condições ambientais (Figura 2). Os valores de luminosidade obtidos para a cv. 'Valência Delta' foram superiores aos encontrados por Leme et al. (2007), que trabalharam com películas comestíveis em laranja 'Pêra' armazenada sob refrigeração e obtiveram valores na faixa de 44 a 48. 
Figura 2 - Luminosidade da casca em laranja 'Valência Delta' armazenada sob condição ambiente com e sem recobrimento

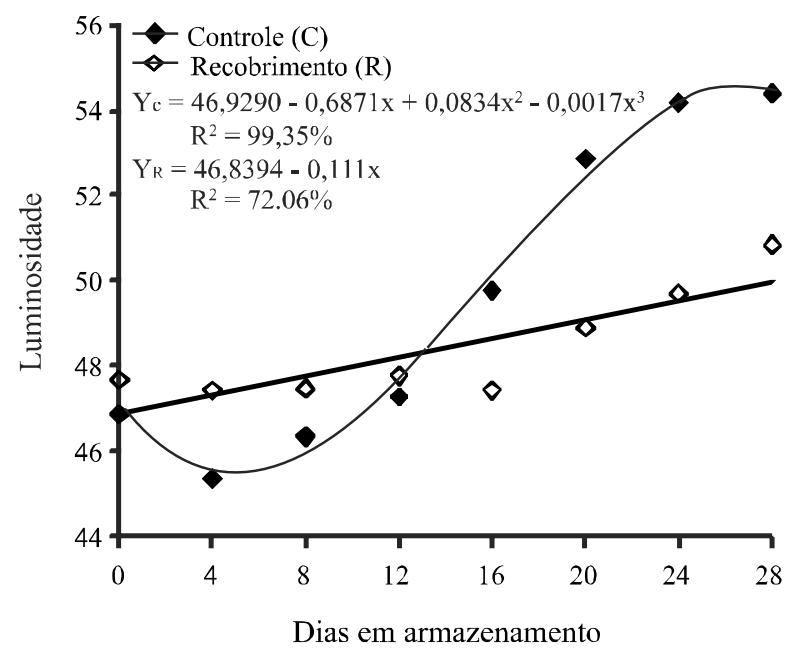

A aplicação de recobrimento preservou a coloração verde do flavedo dos frutos durante o armazenamento $(\mathrm{p}<0,05)$, sugerindo um retardo no desenvolvimento da cor da casca ocasionado pelo processo de amadurecimento do flavedo ao longo do armazenamento (Figura 3).

Para comercialização, esse é um aspecto importante, pois através do uso de recobrimento, os consumidores obterão frutos com maior uniformidade na cor da casca. Malgarim, Cantillano e Treptow

Figura 3 - Ângulo hue de cor do flavedo em laranja 'Valência Delta' armazenada sob condição ambiente com e sem recobrimento

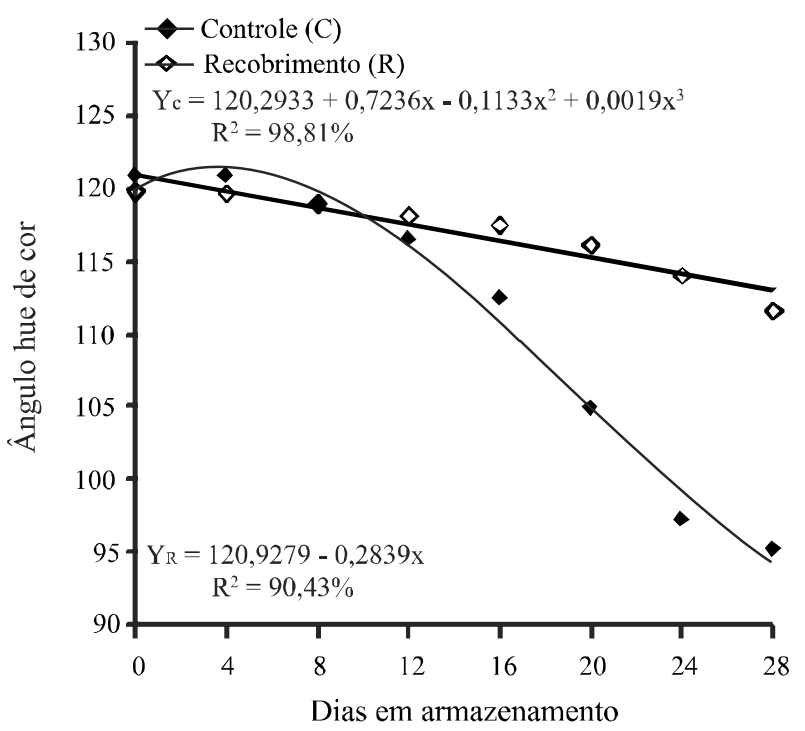

(2007) observaram que a coloração amarela do flavedo intensificou-se durante o armazenamento de laranja doce cv. 'Navelina' e que essa mudança de coloração foi acompanhada pela redução dos valores do ângulo hue de cor.

Assim como observado para os parâmetros de cor luminosidade e ângulo hue de cor, a cromaticidade do flavedo, que indica a intensidade da cor, também foi influenciada pela aplicação do recobrimento (Figura 4).

Figura 4 - Cromaticidade do flavedo em laranja 'Valência Delta' armazenada sob condição ambiente com e sem recobrimento

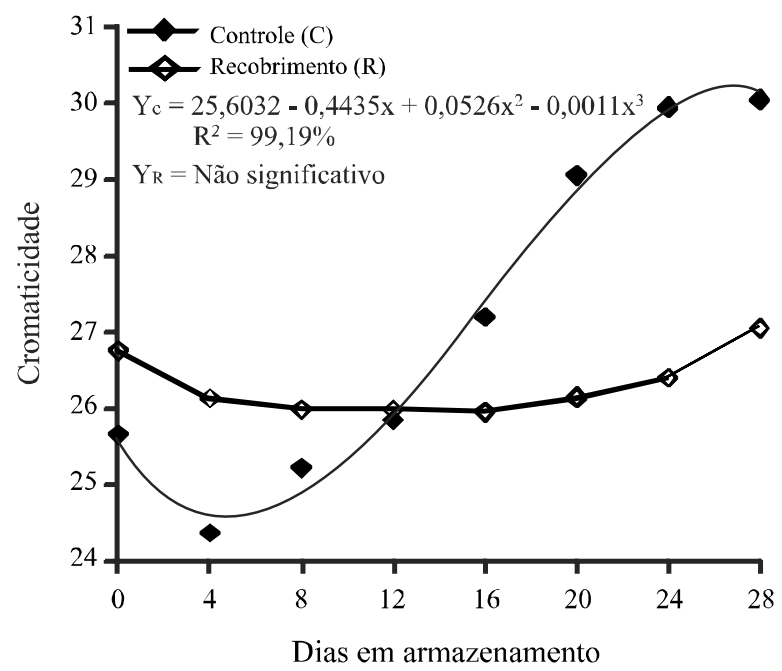

De fato, as tendências de cromaticidade obtidas para os frutos controle e recobertos que são observadas durante o período de armazenamento assemelham-se àquelas obtidas para a luminosidade, sendo inversas às obtidas para o ângulo hue. Juntas, estas tendências confirmam a mudança da coloração verde escuro e intenso para a cor amarela clara e vívida nos frutos controle, bem como a preservação da cor verde nos frutos recobertos.

A aplicação de recobrimento na casca dos frutos da laranja, cultivar 'Valência Delta', reduziu significativamente $(p<0,05)$ a perda de umidade dos frutos (Figura 5).

No inicio do armazenamento, os frutos apresentaram teor de umidade da casca de aproximadamente 69,36\%. Este valor decresceu ao decorrer do período de armazenamento, passando para $61,83 \%$ nos frutos recobertos e para $42,18 \%$ nos frutos controle. Com isso, observou-se que a utilização de recobrimento reduziu significativamente a perda de 
Figura 5 - Umidade da casca em laranja 'Valência Delta' armazenada sob condição ambiente com e sem recobrimento

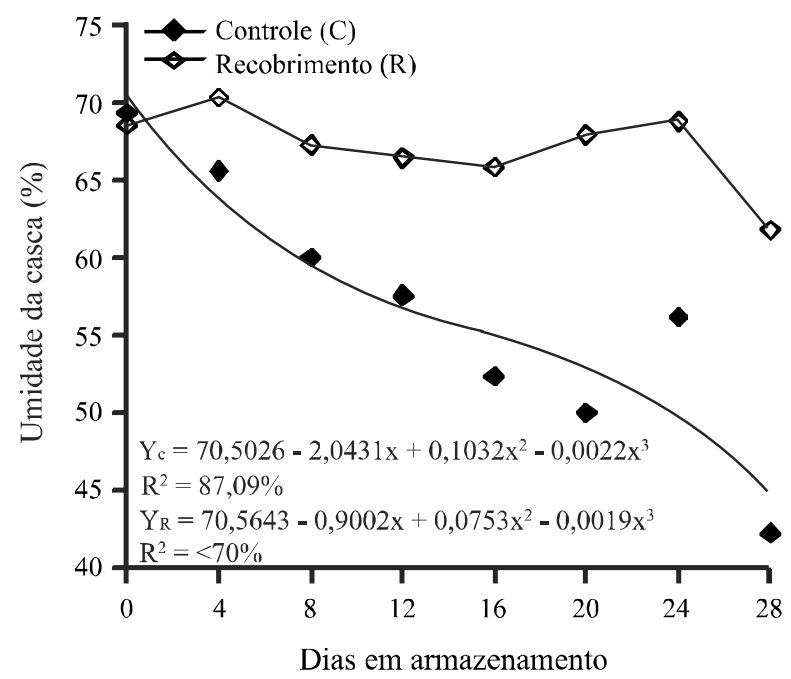

umidade da casca dos frutos. Singh e Reddy (2006) estudaram frutos e cascas de laranjas durante 10 dias de armazenamento sob condição ambiente e refrigerada. Estes autores observaram que a perda de umidade da casca foi de 13 e $3,7 \%$, em condições ambiente e refrigerada respectivamente.

A aplicação de recobrimento não influenciou os teores de sólidos solúveis durante o armazenamento $(\mathrm{p}<0,05)$, pois se mantiveram estáveis durante todo o período de armazenamento (Tabela 1).
Apesar das médias não terem diferido estatisticamente ao nível de $5 \%$ de probabilidade, os frutos controle apresentaram maiores valores de sólidos solúveis, em comparação aos frutos recobertos. Este fato pode estar relacionado à perda de umidade dos frutos durante o período de armazenamento, com subsequente concentração dos sólidos solúveis. Estes resultados corroboram com os reportados por Malgarim, Cantillano e Treptow (2007), em que frutos da cv. 'Navelina' sem recobrimento apresentaram maior conteúdo de sólidos solúveis, em relação aos frutos revestidos com cera. Resultados semelhantes foram encontrados por Couto e Canniatti-Brazaca (2010), que obtiveram valores médios de 10,73 'Brix para cv. 'Valência', ao caracterizarem algumas variedades cítricas.

A acidez titulável foi influenciada pela interação aplicação de recobrimento e período de armazenamento $(\mathrm{p}<0,05)$ (Tabela 1). Observou-se que os valores médios de acidez titulável aumentaram durante o armazenamento, sendo que os frutos controle apresentaram valores entre 0,38 a $0,42 \%$ de ácido cítrico, e os recobertos de 0,38 a $0,45 \%$ de ácido cítrico. De maneira geral, observouse que os frutos com e sem recobrimento apresentaram aumento na acidez titulável, uma característica típica da laranja cv. 'Valência Delta'. Similar aos resultados observados neste estudo, Rapisarda et al. (2008) reportam que, em diferentes condições climáticas, houve aumento nos teores da acidez titulável em estudo realizado com cinco genótipos de laranjas, dentre as quais a variedade 'Valência' foi a única a apresentar aumento nos teores

Tabela 1 - Sólidos solúveis, acidez titulável, relação SS/AT e pH em laranja 'Valência Delta' armazenada sob condição ambiente com e sem recobrimento ${ }^{1}$

\begin{tabular}{|c|c|c|c|c|c|c|c|c|}
\hline \multirow{2}{*}{ Tratamento } & \multicolumn{8}{|c|}{ Dias de armazenamento } \\
\hline & 0 & 4 & 8 & 12 & 16 & 20 & 24 & 28 \\
\hline \multicolumn{9}{|c|}{ Sólidos Solúveis ( ${ }^{\circ}$ Brix $)$} \\
\hline Controle & $9,63 \mathrm{a}$ & $10,40 \mathrm{a}$ & $10,68 \mathrm{a}$ & $10,05 \mathrm{a}$ & $10,35 \mathrm{a}$ & $11,65 \mathrm{a}$ & $11,23 \mathrm{a}$ & $10,13 \mathrm{a}$ \\
\hline Recobrimento & $9,63 \mathrm{a}$ & $10,10 \mathrm{a}$ & $10,35 \mathrm{a}$ & $9,60 \mathrm{a}$ & $10,90 \mathrm{a}$ & $10,08 \mathrm{a}$ & $9,78 \mathrm{a}$ & $10,75 \mathrm{a}$ \\
\hline \multicolumn{9}{|c|}{ Acidez Titulável (\% ácido cítrico) } \\
\hline Controle & $0,38 \mathrm{aA}$ & $0,56 \mathrm{bA}$ & $0,45 \mathrm{aA}$ & $0,44 \mathrm{aA}$ & $0,41 \mathrm{aA}$ & $0,42 \mathrm{aA}$ & $0,55 \mathrm{bA}$ & $0,42 \mathrm{aA}$ \\
\hline Recobrimento & $0,38 \mathrm{aA}$ & $0,35 \mathrm{aB}$ & $0,36 \mathrm{aB}$ & $0,42 \mathrm{aA}$ & $0,48 \mathrm{bA}$ & $0,39 \mathrm{aA}$ & $0,39 \mathrm{aB}$ & $0,45 \mathrm{bA}$ \\
\hline \multicolumn{9}{|c|}{ Relação SS/AT } \\
\hline Controle & $25,64 \mathrm{a}$ & $20,07 \mathrm{a}$ & $26,01 \mathrm{a}$ & $23,43 \mathrm{a}$ & $25,29 \mathrm{a}$ & $27,84 \mathrm{a}$ & $21,58 \mathrm{a}$ & $24,46 \mathrm{a}$ \\
\hline Recobrimento & $25,64 \mathrm{a}$ & $29,68 \mathrm{a}$ & 28,98 a & $23,50 \mathrm{a}$ & $23,57 \mathrm{a}$ & $26,10 \mathrm{a}$ & $25,59 \mathrm{a}$ & $24,68 \mathrm{a}$ \\
\hline \multicolumn{9}{|c|}{$\mathrm{pH}$} \\
\hline Controle & $4,51 \mathrm{a}$ & $4,23 \mathrm{a}$ & $4,28 \mathrm{a}$ & $4,31 \mathrm{a}$ & $4,35 \mathrm{a}$ & $4,33 \mathrm{a}$ & $4,20 \mathrm{a}$ & $4,41 \mathrm{a}$ \\
\hline Recobrimento & $4,51 \mathrm{a}$ & $4,63 \mathrm{a}$ & $4,57 \mathrm{a}$ & $4,33 \mathrm{a}$ & $4,24 \mathrm{a}$ & $4,36 \mathrm{a}$ & $4,50 \mathrm{a}$ & $4,37 \mathrm{a}$ \\
\hline
\end{tabular}

${ }^{1}$ Médias seguidas pela mesma letra minúscula na linha e maiúscula na coluna, não diferem estatisticamente pelo teste de Tukey $(\mathrm{p}<0,05)$. C.V. = 7.75\% (Sólidos solúveis); 6.08\% (Acidez titulável); $16.85 \%$ (Relação SS/AT); 4.57\% (pH) 
de ácido cítrico durante o armazenamento. É importante observar que a acidez da laranja 'Valência Delta', enxertada sobre citrumeleiro 'Swingle', cultivada sob clima quente e seco típico do Estado do Ceará, é menos ácida que a laranja 'Valência' enxertada sobre limoeiro 'Cravo' e cultivada sob clima subtropical (TAZIMA et al., 2008).

As variáveis relação SS/AT e pH (Tabela 1) não diferiram entre os tratamentos aplicados e o período de armazenamento $(\mathrm{p}<0,05)$. Vale ressaltar que a laranja 'Valência Delta' cultivada nas condições climáticas típicas da região de Limoeiro do Norte, Estado do Ceará, apresenta valores médios altos de SS/AT, indicando excelente sabor e equilíbrio entre açúcares e ácidos. Resultados inferiores ao deste experimento foram encontrados por Duzzioni et al. (2010), que analisando laranja 'Valência' obtiveram relação SS/AT de 14,97. Esta diferença nos valores é em função da região produtora e das características da cultivar. $\mathrm{O}$ pH apresentou valores entre 4,51 a 4,41 para os frutos controle e 4,51 a 4,37 para os frutos com recobrimento. No entanto, não foi observada diferença significativa entre estes valores. Rapisarda et al. (2008) trabalharam com cinco variedades de laranjas e observaram que a relação SS/AT e o pH aumentaram durante o armazenamento, com exceção da variedade Valência, cujos teores diminuíram no final do período de armazenamento. Em pesquisa com outras variedades de laranjas, pôde-se observar um comportamento diferente do encontrado na cv. 'Valência Delta'. Malgarim, Cantillano e Treptow (2007) observaram que a relação SS/AT e o pH dos frutos aumentaram durante o armazenamento, sendo que, nas laranjas recobertas com cera ocorreu maior relação SS/AT.
Observou-se que os valores de ácido ascórbico aumentaram durante $\mathrm{o}$ armazenamento, mas não foram influenciados pelo recobrimento e diferiram significativamente durante os dias de armazenamento $(\mathrm{p}<0,05)$ (Tabela 2).

Acréscimo no conteúdo de ácido ascórbico também foi observado por Rapisarda et al. (2008) em estudo com cinco genótipos de laranjas, dentre os quais a variedade 'Valência' apresentou aumento nos teores de ácido ascórbico. Neste estudo, a cv. 'Valência Delta' apresentou valores médios de ácido ascórbico entre 32,50 e 38,25 $\mathrm{mg}$ ácido ascórbico.100 $\mathrm{g}^{-1}$ de suco nos frutos controle, e entre 32,50 e 37,28 mg ácido ascórbico. $100 \mathrm{~g}^{-1}$ de suco para frutos com recobrimento. Estes valores estão dentro da faixa citada por Frata (2006), que analisou sucos e néctares de laranja, obtendo médias de 25,17 a 59,36 mg ácido ascórbico. $100 \mathrm{~g}^{-1}$ de suco. Maiores valores de ácido ascórbico foram encontrados por Lim, Lim e Tee (2007) em estudo comparativo de frutos tropicais, e obtiveram $67 \mathrm{mg}$ ácido ascórbico.100 $\mathrm{g}^{-1}$ de suco na laranja, valor esse superior ao encontrado na laranja 'Valência Delta'. A ingestão diária de ácido ascórbico encontrado nos frutos, incluindo citros, é benéfico à saúde por sua ação vitamínica, ação antioxidante e estímulo ao sistema imunológico.

Os flavonóides amarelos não diferiram entre os frutos controle e os com recobrimento, porém, diferiram significativamente durante os dias de armazenamento (Tabela 2). Foram observados valores médios de 2,51 a 5,47 mg. $100 \mathrm{~g}^{-1}$ para frutos controle; e de 2,51 a 4,56 $\mathrm{mg} .100 \mathrm{~g}^{-1}$ para frutos com recobrimento. Esses valores encontram-se dentro da faixa citada por Pereira (2009),

Tabela 2 - Ácido ascórbico, flavonóides amarelos e polifenóis totais em laranja 'Valência Delta' armazenada sob condição ambiente com e sem recobrimento ${ }^{1}$

\begin{tabular}{|c|c|c|c|c|c|c|c|c|}
\hline \multirow{2}{*}{ Tratamento } & \multicolumn{8}{|c|}{ Dias de armazenamento } \\
\hline & 0 & 4 & 8 & 12 & 16 & 20 & 24 & 28 \\
\hline \multicolumn{9}{|c|}{ Ácido ascórbico (mg ácido ascórbico. $100 \mathrm{~g}^{-1}$ suco) } \\
\hline Controle & $32,50 \mathrm{a}$ & $35,40 \mathrm{ab}$ & $31,75 \mathrm{a}$ & $41,00 \mathrm{~b}$ & $35,75 \mathrm{ab}$ & $40,25 \mathrm{~b}$ & $38,25 \mathrm{ab}$ & $38,25 \mathrm{ab}$ \\
\hline Recobrimento & $32,50 \mathrm{ab}$ & $35,10 \mathrm{abc}$ & $33,73 \mathrm{ab}$ & $38,24 \mathrm{bc}$ & $27,90 \mathrm{a}$ & $41,58 \mathrm{c}$ & $38,80 \mathrm{bc}$ & $37,28 \mathrm{bc}$ \\
\hline \multicolumn{9}{|c|}{ Flavonóides amarelos $\left(\mathrm{mg} .100 \mathrm{~g}^{-1}\right)$} \\
\hline Controle & $2,51 \mathrm{a}$ & $2,54 \mathrm{a}$ & $2,16 \mathrm{a}$ & $2,27 \mathrm{a}$ & $2,14 \mathrm{a}$ & $3,46 \mathrm{a}$ & $3,69 \mathrm{a}$ & $5,47 \mathrm{~b}$ \\
\hline Recobrimento & $2,51 \mathrm{ab}$ & $2,59 \mathrm{a}$ & $1,95 \mathrm{ab}$ & $2,32 \mathrm{ab}$ & $2,22 \mathrm{ab}$ & $2,45 \mathrm{ab}$ & $3,90 \mathrm{bc}$ & $4,56 \mathrm{c}$ \\
\hline \multicolumn{9}{|c|}{ Polifenóis totais (mg GAE.100 $\mathrm{mL}^{-1}$ ) } \\
\hline Controle & $32,47 \mathrm{a}$ & $32,42 \mathrm{a}$ & $32,59 \mathrm{a}$ & $35,96 \mathrm{a}$ & $34,53 \mathrm{a}$ & $35,19 \mathrm{a}$ & $38,50 \mathrm{a}$ & $37,74 \mathrm{a}$ \\
\hline Recobrimento & $32,47 \mathrm{ab}$ & $33,56 \mathrm{ab}$ & $30,39 \mathrm{a}$ & $36,37 \mathrm{ab}$ & $33,26 \mathrm{ab}$ & $31,94 \mathrm{ab}$ & $35,97 \mathrm{ab}$ & $38,48 \mathrm{~b}$ \\
\hline
\end{tabular}

${ }^{1}$ Médias seguidas pela mesma letra, na mesma linha, não diferem estatisticamente pelo teste de Tukey (p<0,05). C.V. = 9.28\% (Ácido ascórbico); 28.32\% (Flavonóides amarelos); $7.46 \%$ (Polifenóis totais) 
que obteve valores de aproximadamente $4,0 \mathrm{mg} .100 \mathrm{~g}^{-1}$ ao analisar laranja proveniente da cidade de Russas.

O conteúdo de polifenóis totais diferiu durante o armazenamento $(\mathrm{p}<0,05)$ nos frutos com recobrimento, apresentando acréscimo ao final do mesmo. Porém, não apresentou diferença significativa entre os frutos controle (Tabela 2). Os frutos com recobrimento apresentaram valores entre 32,47 e $38,48 \mathrm{mg}$ GAE. $100 \mathrm{~mL}^{-1}$, enquanto que os frutos controle apresentam de 32,47 a 37,74 mg GAE.100 mL-1 de suco. Mayuoni et al. (2011) não observaram mudanças no conteúdo de compostos fenólicos ao analisarem a laranja cv. 'Navel' desverdecida.

\section{CONCLUSÃO}

A aplicação do recobrimento à base de cera de carnaúba prolonga a vida útil pós-colheita da laranja cv. 'Valência Delta' cultivada sob as condições climáticas típicas do Estado do Ceará e armazenada sob condição ambiente, com manutenção da massa, preservação da cor do flavedo, redução da perda de umidade da casca e manutenção das propriedades físico-químicas.

\section{AGRADECIMENTOS}

Os autores agradecem à Fundação Cearense de Pesquisa e Desenvolvimento do Estado do Ceará, ao Banco do Nordeste do Brasil e à empresa agrícola Frutacor.

\section{REFERÊNCIAS}

ASSOCIATION OF OFFICIAL ANALYTICAL CHEMISTS. Official methods of analysis. 16. ed. Arlington: AOAC, 1995. $1141 \mathrm{p}$.

AULER, P. A. M.; FIORI-TUTIDA, A. C. G.; SCHOLZ, M. B. S. Qualidade industrial e maturação de frutos de laranjeira 'Valência' sobre seis porta-enxertos. Revista Brasileira de Fruticultura, v. 31, n. 4, p. 1158-1167, 2009.

BUCIC-KOJIC, A. et al. Study of solid-liquid extraction kinetics of total polyphenols from grape seeds. Journal of Food Engineering, v. 81, n. 1, p. 236-242, 2007.

COUTO, M.A. L.; CANNIATTI-BRAZACA, S. G. Quantificação de vitamina $\mathrm{C}$ e capacidade antioxidante de variedades cítricas. Ciência e Tecnologia de Alimentos, v. 30, n. 1, p. 15-19, 2010.

DEPARTAMENTO NACIONAL DE OBRAS CONTRA AS SECAS. Perímetro irrigado Jaguaribe-Apodi. Fortaleza: DNOCS, 2011. Disponível em: <http://www.dnocs.gov.br/ $\sim$ dnocs/doc/canais/perimetros_irrigados/ce/jaguaribe_apodi. html>. Acesso em: 31 ago. 2011.

DUZZIONI, A. G. et al. Determinação da atividade antioxidante e de constituintes bioativos em frutas cítricas. Alimentos e Nutrição, v. 21, n. 4, p. 643-649, 2010.

FRANÇA, F. M. C. Documento referencial do pólo de desenvolvimento integrado baixo Jaguaribe no Estado do Ceará. Disponível em: <http://200.253.194.7/content/ Aplicacao/ET ENE/Rede_Irrigacao/Docs/Documento\%2 Referencial\%20do\%20Polo\%20Baixo\%0Jaguaribe.PDF>. Acesso em: 30 mai. 2010.

FRANCIS, F. J. Analysis of anthocyanins. In: MARKAKIS, P. (Ed.). Anthocyanins as food colors. New York: Academic Press, 1982. p. 181-207.

FRATA, M. T. Sucos de laranja: abordagem química, física, sensorial e avaliação de embalagens. 2006. 228 f. Tese (Doutorado em Ciência de Alimentos) - Universidade Estadual de Londrina, Londrina, 2006.

HAGENMAIER, R. D. A comparison of ethane, ethylene and $\mathrm{CO}_{2}$ peel permeance for fruit with different coatings. Postharvest Biology and Technology, v. 37, n. 1, p. 56-64, 2005.

INSTITUTO ADOLFO LUTZ. Métodos físico-químicos para análise de alimentos. 4. ed. São Paulo, 2004. 1032 p.

JOMORI, M. L. L. et al. Conservação refrigerada de lima ácida 'Tahiti': uso de 1-metilciclopropeno, ácido giberélico e cera. Revista Brasileira de Fruticultura, v. 25, n. 3, p. 406-409, 2003.

LADANIYA, M. S. Citrus fruit: biology, technology and evaluation. Goa, India: Academic Press, 2008. p. 333.

LEME, A. C. et al. Influência do uso de películas comestíveis em laranja pêra minimamente processada. Boletim do Centro de Pesquisa e Processamento de Alimentos, v. 25, n. 1, p. 15-24, 2007.

LIM, Y. Y.; LIM, T. T.; TEE, J. J. Antioxidant properties of several tropical fruits: a comparative study. Food Chemistry, v. 103, n. 3, p. 1003-1008, 2007.

MALGARIM, M. B.; CANTILLANO, R. F. F.; TREPTOW, R. O. Armazenamento refrigerado de laranjas cv. Navelina em diferentes concentrações de cera à base de carnaúba. Acta Scientiarum Agronomica, v. 29, n. 1, p. 99-105, 2007.

MAYUONI, L. et al. Does ethylene degreening affect internal quality of citrus fruit? Postharvest Biology and Technology, v. 62, n. 1 , p. $50-58,2011$.

McGUIRE, R. G. Reporting of objective colour measurements. HortScience, v. 27, n. 12, p. 1254-1255, 1992.

OLIVEIRA, R. P.; NAKASU, B. H.; SCIVITTARO, W. B. Cultivares apirênicas de citros recomendadas para o Rio Grande do Sul. Pelotas: Embrapa Clima Temperado, 2008. 42 p., (Embrapa Clima Temperado, Documento, 195).

PEREIRA, A. C. S. Qualidade, compostos bioativos e atividade antioxidante total de frutas tropicais e cítricas produzidas no Ceará. 2009. 122 f. Dissertação (Mestrado 
em Ciência e Tecnologia de Alimentos) - Universidade Federal do Ceará, Fortaleza, 2009.

RAPISARDA, P. et al. Effect of cold storage on vitamin C, phenolics and antioxidant activity of five orange genotypes [Citrus sinensis (L.) Osbeck]. Postharvest Biology and Technology, v. 49, n. 3, p. 348-354, 2008.

RODOLFO JÚNIOR, F. et al. Caracterização físico-química de frutos de mamoeiro comercializados na EMPASA de Campina Grande-PB. Revista Brasileira de Produtos Agroindustriais, v. 9, n. 1, p. 53-58, 2007.
SINGH, K. K.; REDDY, B. S. Post-harvest physicomechanical properties of orange peel and fruit. Journal of Food Engineering, v. 73, n. 2, p. 112-120, 2006.

STROHECKER, R.; HENNING, H. M. Analisis de vitaminas: métodos comprobados. Madrid: Paz Montalvo, $1967.428 \mathrm{p}$.

TAZIMA, Z. H. et al. Comportamento de clones de laranja 'Valência' na região norte do Paraná. Revista Brasileira de Fruticultura, v. 30, n. 4, p. 970-974, 2008. 